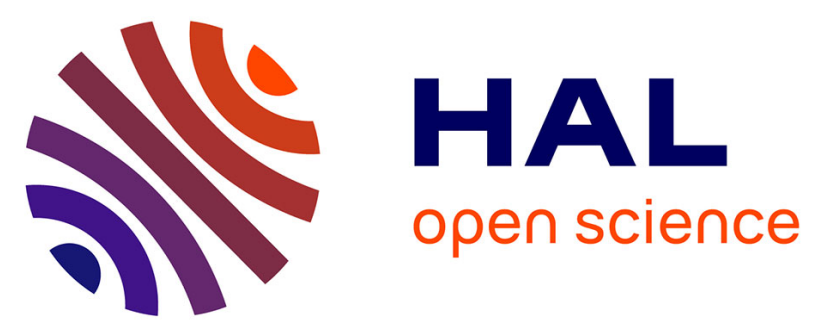

\title{
Ductal Carcinoma In Situ of the breast in younger women: A subgroup of patients at high risk
}

C. Tunon-De-Lara, C. Lemanski, C. Cohen-Solal-Le-Nir, B. de Lafontan, C.

Charra-Brunaud, L. Gonzague-Casabianca, H. Mignotte, E. Fondrinier, S.

Giard, P. Quetin, et al.

\section{To cite this version:}

C. Tunon-De-Lara, C. Lemanski, C. Cohen-Solal-Le-Nir, B. de Lafontan, C. Charra-Brunaud, et al.. Ductal Carcinoma In Situ of the breast in younger women: A subgroup of patients at high risk. EJSO - European Journal of Surgical Oncology, 2010, 36 (12), pp.1165. 10.1016/j.ejso.2010.09.001 . hal-00638137

\section{HAL Id: hal-00638137 https://hal.science/hal-00638137}

Submitted on 4 Nov 2011

HAL is a multi-disciplinary open access archive for the deposit and dissemination of scientific research documents, whether they are published or not. The documents may come from teaching and research institutions in France or abroad, or from public or private research centers.
L'archive ouverte pluridisciplinaire HAL, est destinée au dépôt et à la diffusion de documents scientifiques de niveau recherche, publiés ou non, émanant des établissements d'enseignement et de recherche français ou étrangers, des laboratoires publics ou privés. 


\section{Accepted Manuscript}

Title: Ductal Carcinoma In Situ of the breast in younger women: A subgroup of patients at high risk

Authors: C. Tunon-de-Lara, MD C. Lemanski, MD C. Cohen-Solal-Le-Nir, MD B. de Lafontan, MD C. Charra-Brunaud, MD L. Gonzague-Casabianca, H. Mignotte, MD E.

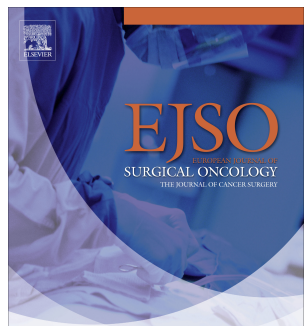
Fondrinier, MD S. Giard, MD P. Quetin, MD H. Auvray, MD B. Cutuli, MD

PII: S0748-7983(10)00500-7

DOI: 10.1016/j.ejso.2010.09.001

Reference: $\quad$ YEJSO 3041

To appear in: European Journal of Surgical Oncology

Received Date: 5 July 2010

Revised Date: 30 August 2010

Accepted Date: 2 September 2010

Please cite this article as: Tunon-de-Lara C, Lemanski C, Cohen-Solal-Le-Nir C, de Lafontan B, CharraBrunaud C, Gonzague-Casabianca L, Mignotte H, Fondrinier E, Giard S, Quetin P, Auvray H, Cutuli B. Ductal Carcinoma In Situ of the breast in younger women: A subgroup of patients at high risk, European Journal of Surgical Oncology (2010), doi: 10.1016/j.ejso.2010.09.001

This is a PDF file of an unedited manuscript that has been accepted for publication. As a service to our customers we are providing this early version of the manuscript. The manuscript will undergo copyediting, typesetting, and review of the resulting proof before it is published in its final form. Please note that during the production process errors may be discovered which could affect the content, and all legal disclaimers that apply to the journal pertain. 


\section{Ductal Carcinoma In Situ of the breast in younger women: a subgroup of patients at high risk}

\section{Running head: DCIS in women under forty}

C.Tunon-de-Lara, $M D^{1}$, C. Lemanski, $\mathrm{MD}^{2}$, C. Cohen-Solal-Le-Nir, $\mathrm{MD}^{3}$, B. de Lafontan, $\mathrm{MD}^{4}$, C. Charra-Brunaud, $\mathrm{MD}^{5}$, L. Gonzague-Casabianca ${ }^{6}$, H. Mignotte, $M D^{7}$, E. Fondrinier, $\mathrm{MD}^{8}$, S. Giard, $\mathrm{MD}^{9}$, P. Quetin, $\mathrm{MD}^{10}$, H. Auvray, MD ${ }^{11}$, B. Cutuli, $M D^{12}$

${ }^{1}$ Institut Bergonié, 229 cours de l'Argonne 33076 Bordeaux Cedex, France, tunon@bergonie.org

${ }^{2}$ Centre Val d'Aurelle, Parc Euromedecine 34298 Montpellier Cedex 5, France clemanski@valdorel.fnclcc.fr

${ }^{3}$ Rene Huguenin Centre, 35 rue Dailly 92210 Saint Cloud, France,

${ }^{4}$ Claudius Regaud Institute, 20-24, rue du Pont Saint Pierre, 31052 Toulouse Cedex, France, delafontan@icr.fnclcc.fr

${ }^{5}$ Alexis Vautrin Centre, avenue de Bourgogne Brabois 54511 Vandoeuvre-les-Nancy Cedex, c.brunaud@nancy.fnclcc.fr

${ }^{6}$ Institut Paoli-Calmette, 232, Boulevard Saint Marguerite BP 156, 13273 Marseille Cedex 9 , gonzaguel@marseille.fnclcc.fr

${ }^{7}$ Léon-Bérard Centre, 28 rue Laennec 69373 Lyon Cedex 08 mignotte@lyon.fnclcc.fr

${ }^{8}$ Paul Papin Centre, 2 rue Moll, 49933 Angers Cedex 09 e.fondrinier@reims.fnclcc.fr

${ }^{9}$ Oscar Lambret Centre, 3 rue Frederic Combemale BP 307, 59020 Lille Cedex, s-giard@o-lambret.fr

${ }^{10}$ Paul Strauss Centre, 3 rue de la Porte de l'hôpital, BP 42, 67065 Strasbourg Cedex, p.quetin@chr-metz-thionville.fr

${ }^{11}$ Jean Perrin Centre, 58 rue Montalembert, 63011 Clermont-Ferrand Cedex 01, hugau@aol.com

${ }^{12}$ Polyclinique de Courlancy, 38 rue de Courlancy, 51100 Reims, bcutuli@iccreims.fr

Correspondence: Christine Tunon-de-Lara, Department of Surgery, Institut Bergonié, 229 cours de l'Argonne 33076 Bordeaux Cedex, France, Tel: +33 (0)5 56333237 - Fax: +33 (0)5 56337882 E-mail: tunon@bergonie.org 


\section{Abstract}

Background: After breast conserving treatment, young age is a predictive factor for recurrence in patients with Ductal Carcinoma In Situ (DCIS) of the breast. The purpose of this study was to evaluate predictive factors for recurrence and outcomes in these younger women (under 40 years) treated for pure DCIS.

Methods: From 1974 to 2003, 207 cases were collected in 12 French Cancer Centers. Median age was 36.3 years and median follow-up 160 months. Seventy four $(35.8 \%)$ underwent mastectomy, 67 (32.4\%) lumpectomy alone and $66(31.9 \%)$ lumpectomy plus radiotherapy.

Results: 37 recurrences occurred (17.8\%): $14(38 \%)$ were in situ and $23(62 \%)$ invasive. After breast conservative treatment $(B C T)$, the overall rate of recurrence was $27 \%$ (33\% in the lumpectomy plus radiotherapy group vs. $21 \%$ in the lumpectomy alone group). Comedocarcinoma subtype $(p=0.004)$, histological size more than $10 \mathrm{~mm}(p=0.011)$, necrosis $(p=0.022)$ and positive margin status $(p=$ 0.019) were statistically significant predictive factors for recurrence. The actuarial 15 -year rates of local recurrence were $29 \%, 42 \%$ and $37 \%$ in the lumpectomy alone, lumpectomy and whole breast radiotherapy and lumpectomy + whole breast radiotherapy with additional boost groups respectively. After recurrence, the 10-year overall survival rate was $67.2 \%$.

Conclusion: High recurrence rates (mainly invasive) after BCT in young women with DCIS are confirmed. BCT in this subgroup of patients is possible if clear and large margins are obtained, tumor size is under $11 \mathrm{~mm}$ and necrosis- and/or comedocarcinoma-free.

Keywords: comedocarcinoma; ductal carcinoma in situ; margin status; radiation therapy; local recurrence; relapse; surgery; young age; breast; and cancer survival 


\section{Introduction}

Ductal carcinoma in situ (DCIS) of the breast is a relatively rare disease in women under 40 years of age (approximately $4 \%$ of a total 7000 breast cancers per year in France) [1], which tends to be diagnosed by clinical findings, incidentally, or after plastic surgery. However, DCIS is generally recognized as a precursor for invasive breast cancer [2,3] and recurrence rates for younger women are high when compared to rates for women over 40 years [4-7]. Among patients with DCIS, mastectomy remains the treatment providing the optimal control rate but breastconserving surgery has been progressively used for several years, owing to a better knowledge of the disease's natural history and an increasing use of screening mammography, allowing the detection of smaller lesions [8]. However, for women under 50 who are not part of French national screening programs and are diagnosed with more advanced tumor stages at diagnosis, greater analysis of predictive factors for recurrence is needed [4].

In invasive cancer, breast carcinoma is recognized as more aggressive and associated with higher mortality and recurrence in young patients [9] and our aim was to investigate whether this was the case for younger women with DCIS. To do this, we analyzed predictive factors for recurrence in these young patients, comparing observed rates with rates reported in the previous mentioned comparative study and in the literature as per Schmidt [10]. The current series represents to our knowledge the largest series of young women with DCIS. This work was motivated by the comparative study undertaken at Institut Bergonié between 731 DCIS patients over 40 and 81 DCIS patients 40 and under. The differences in treatment and prognosis between these two groups motivated us to 
look more closely at this relatively poorly understood subgroup of younger patients, using a larger multi-institutional series.

\section{Patients, material and methods}

\section{Patients}

Institutional review board approval was obtained prior to the commencement of this retrospective study. Written informed consent of patients was not required. This study combines the results of two previously published series of patients with DCIS $[11,12]$. These series describe clinical, demographic and pathologic data for 1558 patients treated for DCIS across 12 Comprehensive Cancer Centers in France from January 1971 to December 1995. All patients with pure DCIS, with no invasion (American Joint Committee on Cancer clinical stage 0: TisN0M0), who were under 40 at the time of diagnosis were included in this study, including type 1 [13]. Patients with synchronous or previous contra-lateral invasive carcinoma were excluded.

\section{Pathology}

Whole lumpectomy specimens were analyzed from 2-mm thick slices. Surgical margins and quality of excision were routinely evaluated in each centre. Histopathology information was retrieved from pathology reports. For each patient we determined pattern, necrosis, margins, tumor size and grade as per Cutuli's recommendations [14].

\section{Treatment}

Patients underwent either lumpectomy or mastectomy according to disease stage. Non-palpable lesions underwent preoperative procedure using mammographic or ultrasonographic guidance. Excised specimens were submitted to radiography to confirm that the non-palpable lesion had been fully removed. Axillary lymph node dissection (ALND) was performed in some cases, but no sentinel node biopsies 
were performed during this period. Lumpectomy patients underwent 50 Grays whole breast irradiation (WBR) in 25 fractions, 5 to 6 weeks after surgery, with an optional additional external or interstitial 10 Gray boost.

Follow-up data was reported yearly for all patients. To determine margin status, surgeons inked the external faces of samples and margins were judged to be free if carcinoma were either not present or were more than $3 \mathrm{~mm}$ from the inked face.

\section{Recurrences}

Ipsilateral local recurrence (LR) was defined as the recurrence of an in situ or invasive cancer in the treated breast. Contra-lateral breast cancer (CBC) was defined as the subsequent development of breast cancer in the opposite, untreated breast (in situ or invasive). Regional recurrence was defined as the occurrence of axillary, supraclavicular or internal mammary chain recurrence and metastatic recurrence was defined as all other events at distance (bone, liver, lung, brain). Local recurrences were detected during clinical examinations or follow-up mammographies. Regional or metastatic recurrences were detected on symptomatic anomalies confirmed by supplementary examinations (such as imaging and pathology where applicable).

\section{Statistical analysis}

Overall survival (OS) and disease-free survival (DFS) rates were calculated from time of diagnosis until date of death, recurrence, or last follow-up if appropriate. The probability of survival or recurrence was calculated using the Kaplan-Meier method. Kaplan-Meier curves were compared using the log-rank procedure. Predictive factors of recurrence were analyzed by univariate analysis. All statistical tests were conducted using SPSS software (version 14.0) Chicago. The chosen significant level was $p<0.05$. 


\section{Results}

\section{Patients, diagnosis and treatment}

A total of 224 patients aged $<40$ years with pure DCIS were included. A subsequent 17 patients were excluded due to synchronous or previous contralateral invasive carcinoma, leaving 207 patients for analysis. Median age at diagnosis was 36.3 years (range: 18-40). DCIS was detected by clinical examination in 104 patients (50\%) (palpable mass $n=62$, nipple discharge $n=39$ or Paget's disease $n=3$ ), by mammographic abnormality for 88 patients (42.8\%) and incidentally in $15(7.2 \%)$. Palpable masses were $>2 \mathrm{~cm}$ for 32 patients, between $1-2 \mathrm{~cm}(n=17)$ and $<1 \mathrm{~cm}(\mathrm{n}=$ 8) (unknown in 5).

Among these 207 patients, 74 (35.8\%) underwent mastectomy (M), 67 (32.4\%) lumpectomy alone (LA), 66 (31.9\%) lumpectomy followed by 50 Grays WBRT and 30 received a 10 Gray additional boost delivered by electrons $(n=24)$, reduced photon fields $(n=4)$ or interstitial implant $(n=2)$. ALND was performed in 82 patients; (respectively $70 \%$ and $22 \%$ of mastectomy and lumpectomy patients). All excised lymph nodes were free of metastasis (pN0). There were 38 immediate (51\%) and 16 delayed (22\%) breast reconstructions. Two patients were prescribed tamoxifen.

\section{Histological findings}

The circumstances of diagnosis and findings on histological examination of the specimen are summarized in Table 1 according to treatment received. Median size was $11 \mathrm{~mm}$. Mastectomy was performed in statistically larger lesions, but diameters were statistically similar between the patients who receive exclusive surgery (LA) or surgery with additional radiotherapy $(L R T)(p=0.46)$. The rate of involved margins was similar in the 2 lumpectomy groups (LA and LRT) with $14 \%$ on average.

Mastectomy patients presented a higher proportion of high-grade lesions. Comedocarcinomas accounted for $22 \%$ overall, but the proportion varied 
significantly according to treatment, from $5 \%$ in lumpectomy to $38 \%$ in the mastectomy group $(p=0.05)$. The rate of necrosis in lumpectomy patients was significantly higher in patients who received postoperative radiotherapy (LRT) than in the lumpectomy alone (LA) group ( $47 \%$ vs. $21 \% \mathrm{p}=0.002)$.

\section{Recurrences}

As shown in Table 2, with a median follow up of 160 months, $95 \% \mathrm{Cl}$ [148.96172.69], 37 patients (17.8\%) presented local recurrence (LR). Thirty six of them occurred in the breast-conserving treatment $(\mathrm{BCT})$ group (local recurrence rate $=$ $27 \%$ ) and one occurred for a mastectomy patient. Recurrences were invasive in 7/14 LA patients and 15/22 LRT patients. For the 40 patients with recurrence, median time to recurrence was 56 months (min/max: 6.6 - 165.8 months).

\section{Contra-lateral breast cancer}

Overall, 18 patients (8.6\%) subsequently developed a contralateral breast cancer (CBC), which was non-invasive in 9 patients and invasive in 8 patients. Information was missing for one patient.

\section{Outcome after recurrences}

Recurrence was treated by salvage mastectomy alone in 24 cases (11 LA and 13 LRT), by breast conservative surgery in 4 cases in the LA group and by a combination of surgery, radiotherapy, chemotherapy and/or hormonotherapy in the other 12 patients. Outcomes are given in Table 3.

The mastectomy patient who relapsed developed axillary node involvement two years later. Another mastectomy patient also developed an axillary node recurrence but without earlier LR. A third mastectomy patient developed metastases without either previous local or regional recurrence.

Of the 7 LA patients with invasive LR, 4 developed axillary node involvement (3 simultaneously) and one subsequently developed metastases. One further patient developed metastases without previous loco regional recurrence. Another patient 
with local recurrence who refused treatment, developed invasive disease and died from metastases. Among the LRT patients, 1/7 with in situ LR and 2/14 with invasive LR developed axillary node involvement, 6/15 developed metastases after invasive LR.

Among the 37 loco-regional recurrences, 10 patients died from metastatic disease: 3/74 M patients, 1/67 LA patient and 6/66 LRT patients. In patients with relapses, the 10 -year survival rate was $67.2 \%$ compared to $98 \%$ overall for patients with no recurrences. The 10-year global breast-specific survival rates after M, LA or LRT were $98.4 \%, 98.2 \%$ and $94.7 \%$ respectively.

\section{Predictive factors of recurrence}

The following were significant independent predictive factors of local recurrence: comedocarcinoma $(p=0.004)$, histological size $>10 \mathrm{~mm} \quad(p=0.011)$, necrosis $(p=0.022)$ and positive margins $(p=0.019)$ (Figure 1$)$. As necrosis was much higher in the LA group than in the LRT group, we also looked at actual rates of recurrence according to treatment group and presence of necrosis. There were more recurrences when necrosis was present for the LA group (61.5\%) vs. when necrosis was not present in the same group (14\%). The was no difference between recurrence rates according to presence of necrosis in the LRT group (32.1\% recurrence with necrosis, $31.3 \%$ without).

The following factors were not predictive of local recurrence: age under $35(n=82)$ $(p=0.32)$, tumor grade $(p=0.19)$ and radiotherapy with $(p=0.62)$ or without boost $(p=0.33)$ (Figure 2). We also tested for age-based recurrence rate differences with the log-rank test finding no differences between local recurrence rates for women $<35$ years $(n=82)$ and women $\geq 35$ years $(n=126)$. 


\section{Discussion}

Despite the fact that our series is a retrospective, multicentre series, this ensured that we had a large enough sample to make statistical comparisons. To our knowledge, this study is the largest series of patients with DCIS aged under 40 published in the literature. Based on an incidence rate of $4 \%$ of DCIS patients aged younger than 40 , our series of 207 patients under 40 years of age represents in theory a sample of over 5000 women with DCIS. These results can be directly compared to other studies comparing outcomes for older vs. younger DCIS patients. These results coming from a large series are important as they strictly defined inclusion and tested for age under 35 as a predictive factor in an attempt to identify an appropriate cut-off age.

\section{Survival}

The 10-year OS rate after a diagnosis of DCIS and salvage therapy after breast failure has frequently been reported at $94 \%$ or more[12, 15-17]. In our series, patients with recurrence had worse prognosis than patients without recurrence. The 10-year actuarial OS rate after recurrence was much lower at $67.2 \%$ (compared to $98 \%$ for recurrence-free patients). For older women this difference between survival rates is not generally observed with overall rates around $96-98 \%$ for recurrence and recurrence-free [2]. In our series of young patients, we observed an increase of breast cancer death when local recurrence occurred. Young patients often had symptomatically-detected lesions. However, young patients did not have higher grade DCIS compared to older patients, which is in concordance with two other reports $[15,18]$.

\section{Diagnosis and recurrence}

In our study, diagnosis was performed on clinical findings in $50 \%$ of patients. This rate is comparable to Bijker et al's [4, 15] findings that younger women have a 
higher rate of symptomatically-detected lesions ( $66 \%$ vs. $25 \%$ of women older than 40) because they do not undergo routine mammograms. Patients underwent the 3 classical treatment modalities in approximately the same percentages compared to rates reported in the literature of up to $50 \%$ for mastectomies [19].

The rate of $\mathrm{CBC}$ observed (8.6\%) in our sample is similar to rates described in the literature $(3-9 \%)[12,15,16,20,21]$. No positive lymph nodes were found in this series, confirming that ALND is not a suitable treatment for young patients with pure DCIS. The 10-year actuarial recurrence rates were $3.3 \%(M), 23 \%(L A), 35.6 \%$ (LRT) and 29.9\% (LRT and boost). These are similar to rates reported in the EORTC trial for younger women (34\% at 10 years overall) [15].

\section{Predictive factors for recurrence}

Four predictive factors for recurrence were identified in our series of women $<40$ years with DCIS. According to previously published studies, margin status appears to be the most constant predictive factor of recurrence[7, 8, 12, 22-24]. Indeed, free margins appear difficult to obtain. Bijker et al described in an international randomized trial $27 \%(11 / 41)$ of involved margin status in young patients compared to $22 \%(157 / 700)$ in women older than 40 years of age [15]. Vicini $[17,24]$ explained the higher rate of recurrences in young women by a total volume of re-excision less than $60 \mathrm{ml}$. Wazer et al showed in their series a greater likelihood of having a tumor on re-excision in young patients as compared with patients older than 45 years of age [25]. It is likely in our series that a breast-conserving treatment was proposed more frequently to young patients whatever the size and margin status of DCIS and the size of the breast. Only $14.2 \%$ of patients had positive margins, and they were consistently distributed among the LA (8 cases, 12\%) and LRT (11 cases, 16\%) groups. Despite the small number of patients with positive margins, this factor is one of the most important predictive factors of recurrence and the only one that can 
be controlled by clinicians. Clearly, radiotherapy does not compensate for surgical margins which are not free of cancer. In the MD Anderson study, Jhingran et al concluded that patient age does not affect outcome, if the margins were free [16]. More research is required here; and particularly in the definition of 'free margins' [26]. Recent French guidelines recommend $2 \mathrm{~mm}$ [27] based on the meta-analysis by Dunne [28] indicating that outcomes with $2 \mathrm{~mm}$ surgical margins were comparable to outcomes with wider margins.

Comedocarcinoma was also found to be a predictive factor for recurrence, but this was also associated with high grade and necrosis which may partially account for this higher rate of recurrence. In agreement with Rogrigues et al's [29] findings, the multivariate analysis showed the presence of necrosis to be a significant predictor for local recurrence. Finally, tumor size $>10 \mathrm{~mm}$ was found to be a predictive factor for local recurrence in our series, in contrast to Vicini et al. [17] who noted more tumors $>10 \mathrm{~mm}$ in patients younger than 45 years but that this factor did not increase risk of local recurrence. The small number of patients (31) could explain the lack of difference observed in their series.

\section{Impact of radiotherapy}

Unlike in other series $[6,11,15,18,21,30]$, radiation therapy with or without boost did not reduce the incidence of local recurrences. In the EORTC trial, radiotherapy reduced the risk of local recurrences, but this decrease was less important in young patients than in older patients [15]. In a recent retrospective study, Omlin et al. [30] described a potential link between the radiotherapy dose and the local recurrence rate in women 45 years or younger with DCIS. These results have to be confirmed with on-going phase III prospective trials evaluating potential benefits of additional boost and stratified by age. Rudloff et al. [31] recently reported that recurrence risk 
remains substantial even with free margins and that radiotherapy reduced the risk of recurrence particularly for patients in at risk subgroups, including younger women.

\section{Conclusions}

Patients under 40 with DCIS constitute a particularly poor prognosis group with a higher risk of recurrence and poorer survival. We describe a lower 10-year survival rate after local relapse than those previously reported in the literature. Our data provide further supporting evidence that younger women are at higher risk of local recurrence of DCIS than older women, as has been suggested in previous series. Age appears to be one more parameter that should be considered in the complex decision-making process if we want to reduce local recurrence risks, thus improving chances for survival.

We recommend to limit the use of a safe conservative surgery to tumors with margins $\geq 2 \mathrm{~mm}$, DCIS size $11 \mathrm{~mm}$ or smaller and free of necrosis and comedocarcinoma. Mastectomy ought to be proposed in cases of multifocal DCIS, tumors larger than $10 \mathrm{~mm}$, positive margins after re-excision, DCIS with necrosis or comedocarcinoma or small breasts (ruling out efficient surgery).

Mastectomy and immediate breast reconstruction should be proposed for patients with all poor predictive factors. Oncoplastic surgery techniques may offer promising alternatives to mastectomy to obtain large free margins. In all cases, the treatment procedure should be explained to the patient and the treatment should be chosen by the patient in consultation with the medical team (radiologist, surgeon, pathologist and oncologist). 


\section{Acknowledgements}

The authors wish to thank Veronique Brouste for her technical assistance in data management; Diane Penet, Brian Collins and Pippa McKelvie-Sebileau for their help in the preparation of this article. 


\section{References}

1. Cutuli B, Cottu PH, Guastalla JP, et al. A French national survey on infiltrating breast cancer: analysis of clinico-pathological features and treatment modalities in 1159 patients. Breast Cancer Res Treat 2006; 95: 55-64.

2. Allegra CJ, Aberle DR, Ganschow P, et al. National Institutes of Health Stateof-the-Science Conference statement: Diagnosis and Management of Ductal Carcinoma In Situ September 22-24, 2009. J Natl Cancer Inst 2010; 102: 161 9.

3. Virnig BA, Tuttle TM, Shamliyan T, et al. Ductal Carcinoma In Situ of the Breast: A Systematic Review of Incidence, Treatment, and Outcomes. J Natl Cancer Inst 2010; 102: 170-8.

4. Bijker N, Peterse JL, Duchateau L, et al. Risk factors for recurrence and metastasis after breast-conserving therapy for ductal carcinoma-in-situ: analysis of European Organization for Research and Treatment of Cancer Trial 10853. J Clin Oncol 2001; 19: 2263-71.

5. Schouten van der Velden AP, Peeters PH, Koot VC, et al. Local recurrences after conservative treatment of ductal carcinoma-in-situ of the breast without radiotherapy: the effect of age. Ann Surg Oncol 2006; 13: 990-8.

6. Solin LJ, Fourquet A, Vicini FA, et al. Long-term outcome after breastconservation treatment with radiation for mammographically detected ductal carcinoma in situ of the breast. Cancer 2005; 103: 1137-46.

7. Van Zee KJ, Liberman L, Samli B, et al. Long term follow-up of women with ductal carcinoma in situ treated with breast-conserving surgery: the effect of age. Cancer 1999; 86: 1757-67.

8. Cutuli B, Cohen-Solal-le-Nir C, de-Lafontan B, et al. Breast-conserving therapy for ductal carcinoma in situ of the breast: the French Cancer Centers' experience. Int J Radiat Oncol Biol Phys 2002; 53: 868-79.

9. Bollet MA, Sigal-Zafrani B, Mazeau V, et al. Age remains the first prognostic factor for loco-regional breast cancer recurrence in young ( $<40$ years) women treated with breast conserving surgery first. Radiother Oncol 2007; 82: 272-80.

10. Schmidt RT, Tsangaris TN, Cheek JH. Breast cancer in women under 35 years of age. Am J Surg 1991; 162: 197-201.

11. Cutuli B, Fay R, Cohen-Solal-le-Nir C, et al. [Ductal carcinoma in situ of the breast. Analysis of 882 cases]. Presse Med 2004; 33: 83-9.

12. Tunon-de-Lara C, de Mascarel I, MacGrogan G, et al. Analysis of 676 cases of ductal carcinoma in situ of the breast from 1971 to 1995: diagnosis and treatment--the experience of one institute. Am J Clin Oncol 2001; 24: 531-6. 
13. de M, I, MacGrogan G, Mathoulin-Pelissier S, et al. Breast ductal carcinoma in situ with microinvasion: a definition supported by a long-term study of 1248 serially sectioned ductal carcinomas. Cancer 2002; 94: 2134-42.

14. Cutuli B, Fourquet A, Luporsi E, et al. [Standards, Options and Recommendations for the management of ductal carcinoma in situ of the breast (DCIS): update 2004]. Bull Cancer 2005; 92: 155-68.

15. Bijker N, Meijnen P, Peterse JL, et al. Breast-conserving treatment with or without radiotherapy in ductal carcinoma-in-situ: ten-year results of European Organisation for Research and Treatment of Cancer randomized phase III trial 10853--a study by the EORTC Breast Cancer Cooperative Group and EORTC Radiotherapy Group. J Clin Oncol 2006; 24: 3381-7.

16. Jhingran A, Kim JS, Buchholz TA, et al. Age as a predictor of outcome for women with DCIS treated with breast-conserving surgery and radiation: The University of Texas M. D. Anderson Cancer Center experience. Int J Radiat Oncol Biol Phys 2002; 54: 804-9.

17. Vicini FA, Kestin LL, Goldstein NS, et al. Impact of young age on outcome in patients with ductal carcinoma-in-situ treated with breast-conserving therapy. $J$ Clin Oncol 2000; 18: 296-306.

18. Fowble $B$, Hanlon AL, Fein DA, et al. Results of conservative surgery and radiation for mammographically detected ductal carcinoma in situ (DCIS). Int $J$ Radiat Oncol Biol Phys 1997; 38: 949-57.

19. Kricker A, Goumas C, Armstrong B. Ductal carcinoma in situ of the breast, a population-based study of epidemiology and pathology. Br J Cancer 2004; 90: $1382-5$.

20. Cutuli B, Cohen-Solal-le-Nir C, de Lafontan B, et al. Ductal carcinoma in situ of the breast results of conservative and radical treatments in 716 patients. Eur $J$ Cancer 2001; 37: 2365-72.

21. Fisher ER, Land SR, Fisher B, et al. Pathologic findings from the National Surgical Adjuvant Breast and Bowel Project: twelve-year observations concerning lobular carcinoma in situ. Cancer 2004; 100: 238-44.

22. Silverstein MJ, Lagios MD, Groshen S, et al. The influence of margin width on local control of ductal carcinoma in situ of the breast. N Engl J Med 1999; 340: 1455-61.

23. Turaka A, Freedman GM, Li T, et al. Young age is not associated with increased local recurrence for DCIS treated by breast-conserving surgery and radiation. J Surg Oncol 2009; 100: 25-31.

24. Vicini FA, Recht A. Age at diagnosis and outcome for women with ductal carcinoma-in-situ of the breast: a critical review of the literature. J Clin Oncol 2002; 20: 2736-44. 
25. Wazer DE, Schmidt-Ullrich RK, Ruthazer R, et al. The influence of age and extensive intraductal component histology upon breast lumpectomy margin assessment as a predictor of residual tumor. Int $J$ Radiat Oncol Biol Phys 1999; 45: 885-91.

26. Schwartz GF, Solin LJ, Olivotto IA, et al. The Consensus Conference on the treatment of in situ ductal carcinoma of the breast, April 22-25, 1999. Hum Pathol 2000; 31: 131-9.

27. Kaufmann M, Morrow M, von MG, et al. Locoregional treatment of primary breast cancer: consensus recommendations from an International Expert Panel. Cancer 2010; 116: 1184-91.

28. Dunne C, Burke JP, Morrow M, et al. Effect of margin status on local recurrence after breast conservation and radiation therapy for ductal carcinoma in situ. J Clin Oncol 2009; 27: 1615-20.

29. Rodrigues NA, Dillon D, Carter D, et al. Differences in the pathologic and molecular features of intraductal breast carcinoma between younger and older women. Cancer 2003; 97: 1393-403.

30. Omlin A, Amichetti M, Azria D, et al. Boost radiotherapy in young women with ductal carcinoma in situ: a multicentre, retrospective study of the Rare Cancer Network. Lancet Oncol 2006; 7: 652-6.

31. Rudloff U, Brogi E, Reiner AS, et al. The influence of margin width and volume of disease near margin on benefit of radiation therapy for women with DCIS treated with breast-conserving therapy. Ann Surg 2010; 251: 583-91. 
Table 1. Patient characteristics

\begin{tabular}{llccccc}
\hline & & $\mathrm{M}$ & $\mathrm{LA}$ & \multicolumn{2}{c}{ LRT } & \multicolumn{2}{c}{ Total } \\
\hline \multirow{3}{*}{ Diagnosis } & & $\mathrm{N}=74$ & $\mathrm{~N}=67$ & $\mathrm{~N}=66$ & $\mathrm{~N}=207$ & $(\%)$ \\
& Mammogram & 31 & 22 & 35 & 88 & $(42.5)$ \\
& Clinical & 37 & 38 & 29 & 104 & $(50.2)$ \\
Architectural & Incidental & 6 & 7 & 2 & 15 & $(7.3)$ \\
Subtype & Comedo & 28 & 3 & 15 & 46 & $(22.2)$ \\
& No comedo & 46 & 64 & 51 & 161 & $(77.8)$ \\
Grade & Low & 17 & 30 & 18 & 65 & $(31.4)$ \\
$(\mathrm{n}=108)$ & Intermediate & 8 & 4 & 2 & 14 & $(6.8)$ \\
& High & 19 & 5 & 5 & 29 & $(14.0)$ \\
Histological & Unknown & - & - & - & 99 & $(48.3)$ \\
size & $<10 m m$ & 8 & 25 & 25 & 58 & $(28.0)$ \\
$(\mathrm{n}=117)$ & $>10 m m$ & 30 & 12 & 17 & 59 & $(28.5)$ \\
& Unknown & - & - & - & 190 & $(43.5)$ \\
Necrosis & Yes & 38 & 13 & 28 & 72 & $(34.8)$ \\
$(\mathrm{n}=192)$ & No & 31 & 50 & 32 & 120 & $(58.0)$ \\
& Unknown & - & - & - & 15 & $(7.3)$ \\
Margins & Free & - & 59 & 55 & 114 & $(55.1)$ \\
status & Positive & - & 8 & 11 & 19 & $(9.2)$ \\
$(\mathrm{n}=133)$ & Unknown & - & - & - & 74 & $(35.8)$ \\
\hline
\end{tabular}

$M=$ mastectomy, LA=lumpectomy alone, LRT= lumpectomy and radiotherapy. 
Table 2. First recurrence for DCIS patients under 40 years of age according to treatment

\begin{tabular}{lllll}
\hline & $\mathrm{M}$ & $\mathrm{LA}$ & $\mathrm{LRT}$ & All \\
\hline & $(\mathrm{N}=74)$ & $(\mathrm{N}=67)$ & $(\mathrm{N}=66)$ & $(\mathrm{N}=207)$ \\
LR alone & 1 & 11 & 21 & 33 \\
- In situ & 0 & 7 & 7 & 14 \\
- Invasive & 1 & 4 & 14 & 19 \\
LR+Nodal recurrence & 0 & 3 & 1 & 4 \\
Nodal recurrence alone & 1 & 0 & 0 & 1 \\
Metastasis & 1 & 1 & 0 & 2 \\
\hline
\end{tabular}

$\mathrm{M}=$ mastectomy, $\mathrm{LA}=$ lumpectomy alone, $\mathrm{LRT}=$ lumpectomy and radiotherapy, $\mathrm{LR}=$ local recurrence 
Table 3. Outcomes for DCIS patients under 40 years of age at median follow-up of 160 months and recurrence rate according to outcomes

\begin{tabular}{|c|c|c|c|c|c|c|c|}
\hline Outcome & $\begin{array}{l}\text { Alive } \\
(n=162)\end{array}$ & $\begin{array}{c}\text { Alive with } \\
\text { breast } \\
\text { cancer } \\
(n=3)\end{array}$ & $\begin{array}{l}\text { Alive with } \\
\text { other } \\
\text { cancer } \\
(n=2)\end{array}$ & $\begin{array}{c}\text { Death from } \\
\text { breast } \\
\text { cancer } \\
(n=10)\end{array}$ & $\begin{array}{l}\text { Death } \\
\text { other } \\
\text { cause } \\
(n=4)\end{array}$ & $\begin{array}{l}\text { Lost to } \\
\text { follow up } \\
(n=26)\end{array}$ & $\begin{array}{c}\text { Total } \\
(n=207)\end{array}$ \\
\hline \multicolumn{8}{|l|}{ Treatment Group } \\
\hline - Mastectomy (M) & 67 & 0 & 0 & 3 & 0 & 4 & 74 \\
\hline - Lumpectomy alone (LA) & 48 & 1 & 1 & 1 & 3 & 13 & 67 \\
\hline - Lumpectomy with radiotherapy (LRT) & 47 & 2 & 1 & 6 & 1 & 9 & 66 \\
\hline Recurrence (\%) & $(14.2)$ & $(66.7)$ & $(0)$ & $(100)$ & $(50)$ & $(11.5)$ & (19.3) \\
\hline
\end{tabular}


Figure 1. Overall survival for women $\leq 40$ years

with ductal carcinoma in situ (DCIS) over full follow-up.

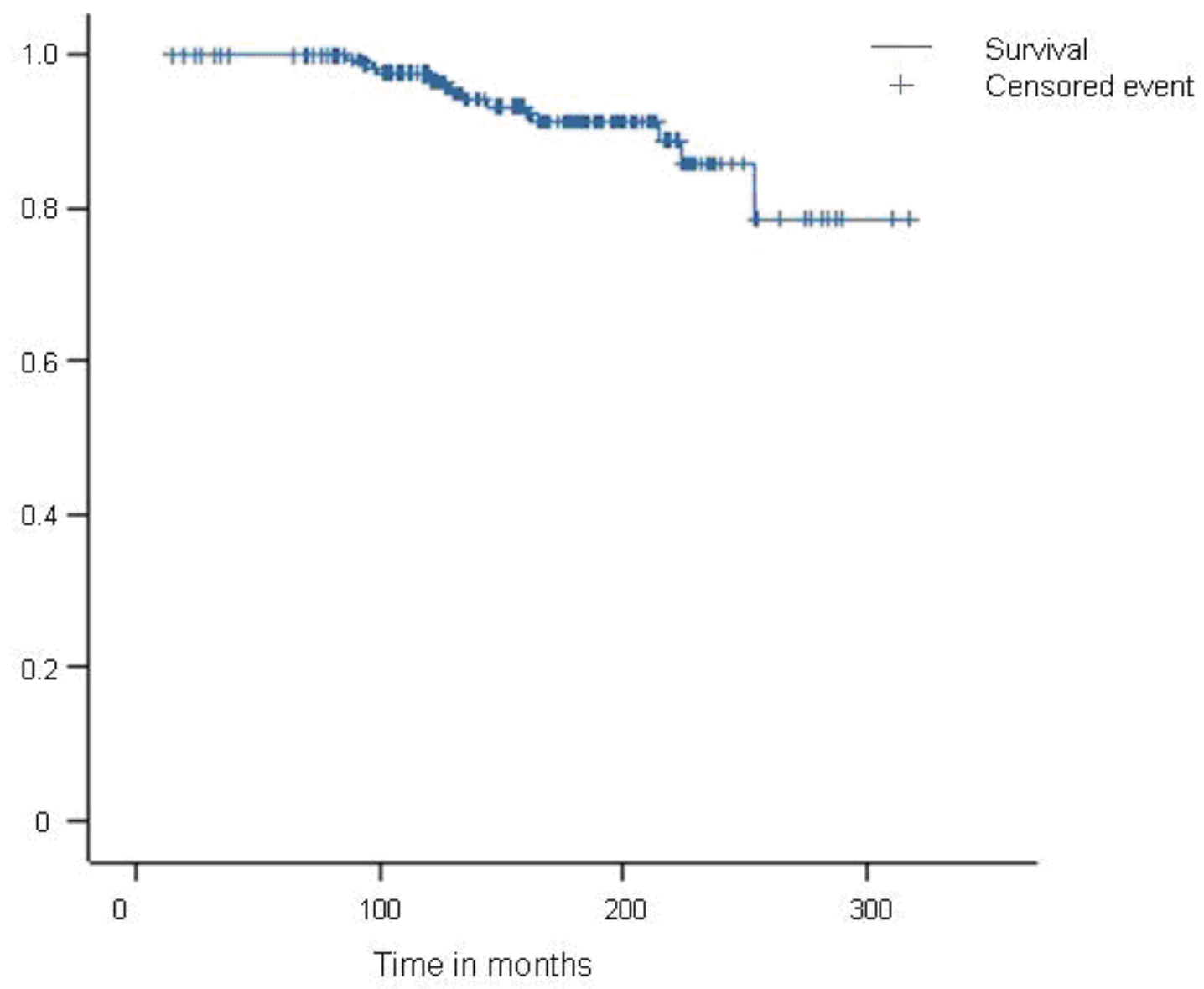

Mean survival in months 290.54 [ $95 \% \mathrm{Cl} 276.8-304.3]$

\begin{tabular}{lccccccc} 
& \multicolumn{8}{c}{ Months } \\
\hline & 0 & 50 & 100 & 150 & 200 & 250 & 310 \\
\hline At risk & 207 & 198 & 172 & 105 & 49 & 12 & 1 \\
Cumul. events & 0 & 0 & 4 & 10 & 12 & 14 & 15
\end{tabular}


Figure 2. Probability of non-recurrence for women $\leq 40$ years with ductal carcinoma in situ (DCIS)

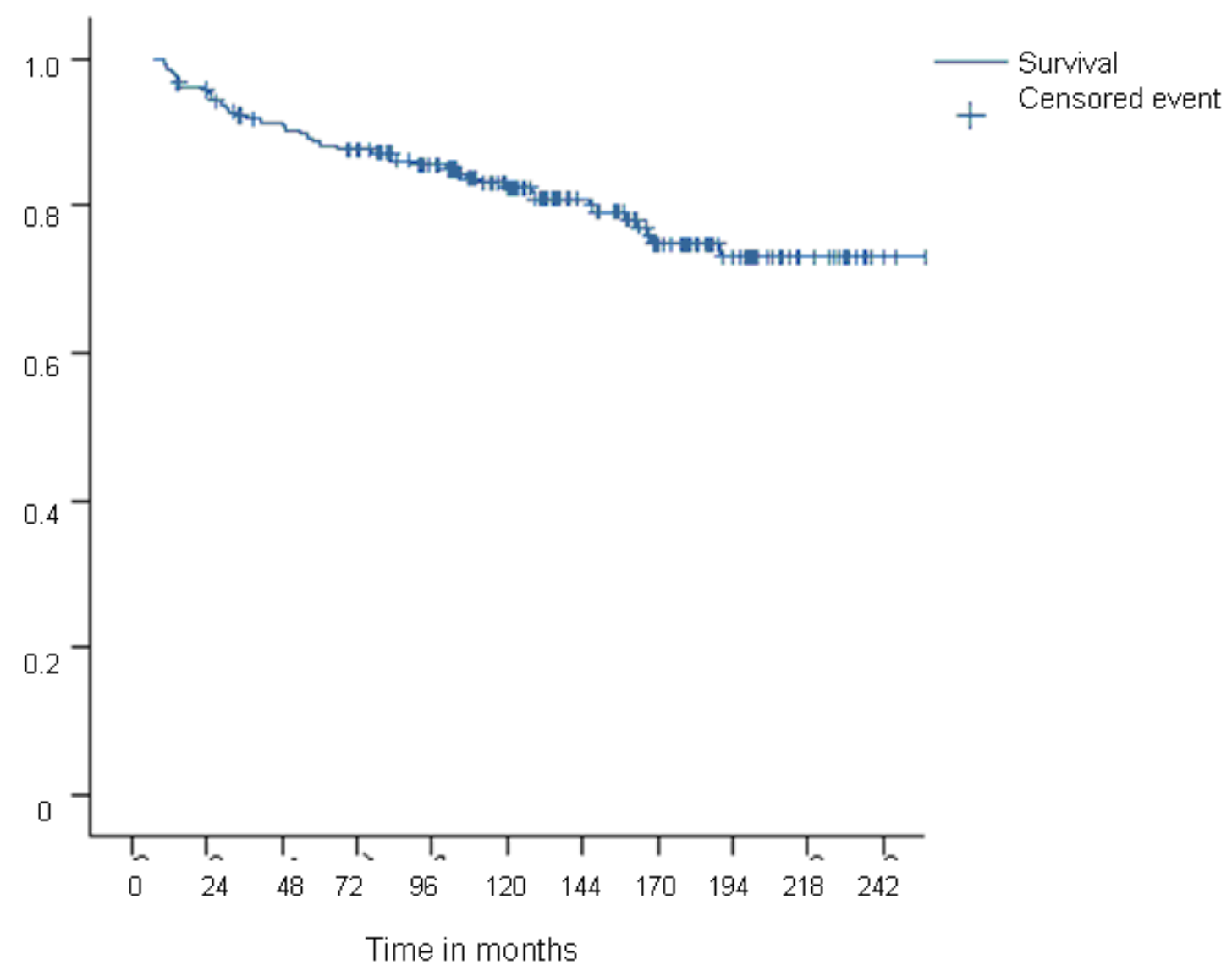

Mean survival $250.43 \quad[95 \% \mathrm{Cl} 234.6-266.2]$

\begin{tabular}{lccccccc} 
& \multicolumn{8}{c}{ Months } \\
\hline & 0 & 50 & 100 & 150 & 200 & 250 & 310 \\
\hline & 208 & 179 & 148 & 83 & 32 & 9 & 2 \\
At risk & 0 & 20 & 29 & 38 & 43 & 43 & 43
\end{tabular}

